\title{
Research Status and Prospect of Orienteering At Home and Abroad
}

\author{
Xiaojun LI \\ Yichun University, Yichun, Jiangxi, China \\ 51270505@qq.com
}

\begin{abstract}
Research status of orienteering at home and abroad, including teaching, training, sport injury and map composition, is discussed through literature review. According to literature review, China is in its initial stage in studying orienteering, but foreign countries have reported deep researches, especially in skill training. Many experts analyzed orienteering from the perspective of cognitive psychology. Intelligence-based research on direction movement is still the future development trend.
\end{abstract}

Index Terms -Orienteering; Research Status; Prospect

\section{Orienteering}

Orienteering is a sport that requires participant to visit all indicated points on the map in order in the shortest time under the assistance of map and compass. All ages and groups could participate in orienteering. As a sport integrating intelligence and physical strength, it requires athletes to have not only certain endurance, but also special intelligence in quick map reading, terrain observation and orientation. There are many types of orienteering. This paper refers to off-road orienteering which can be further divided into hiking orienteering and vehicle orienteering.

\section{A. Origin of orienteering}

"Orienteering" was used for the first time in 1886. It means to cross unknown regions under the assistance of map and compass. Orienteering originated from Sweden and was a military activity at the beginning. In 1895, orienteering was carried out in Stockholm military camp (Sweden) and Oslo military camp (Norway). When soldiers took "orienteering" as a military training activity, one person named Ernst Killander played it as a game. In 1918, Ernst Killander who was the leader of boy scouts in Sweden organized a "Treasure Hunt" activity, which attracted wide interests from people. This is the prototype of "orienteering" sport. In 1919, the world first relative formal orienteering was carried out in one military camp in Scandinavian Peninsula.

\section{B. Development of orienteering}

Orienteering became popular as a sport in Northern Europe in the beginning of 20th century. By 1930s, it has become a popular activity in various Northern European countries, such as Finland, Norway, Sweden, Denmark, etc. In 1943, orienteering was brought into England by the Norway rebels who were quartering at the England. In 1946, American boy scouts introduced the orienteering. Subsequently, it was introduced into Canada, Australia, Germany and France.

To adapt to the world-wide popularization and development of orienteering, an International Orienteering Federation (IOF) was founded in the capital of Denmark ------ Copenhagen on May, 1961. Formal competition items and a series of competition rules as well as technical manuals were determined and established. So far, more than 60 countries in the world have joined in the IOF. IOF was admitted by the International Olympic Committee in 1977. The first World Orienteering Championship (WOC) was held in Finland in 1966. Conseil International Du Sport Militaire (CISM) also takes orienteering as one of formal competition items and enlists it into the seven competition items of CISM championship with basketball. Currently, orienteering is attracting more and more people in Northern Europe and has become one important outdoor activity.

Hong Kong is the first region in China that plays orienteering. Orienteering was introduced into Chinese mainland in 1983. People's liberation army military academies are the "pioneers" of orienteering in Chinese mainland. On March, 1983, Physical Education College of the People's Liberation Army organized the first "orienteering game" in Baishan Mountain, Guangzhou. This is the first orienteering competition in Chinese mainland. In 1994, China held the first national orienteering championship in Beijing. After dozenyear development, orienteering is flourishing in China. China sends several teams to participate in international orienteering competitions every year.

\section{Research status of orienteering}

Although only few research achievements on orienteering have been reported in China, many experts studied orienteering deeply from different perspectives. Research fields mainly can be divided into following five classes: (1) research on implementation, popularization and teaching of orienteering; (2) research on physical ability of orienteering; (3) research on skills of orienteering; (4) research on injuries of orienteering; (5) research on orienteering map.

\section{A. Implementation and teaching of orienteering}

There are abundant research data on implementation and teaching of orienteering. Since orienteering is a relative new sport in China, most existing researches focus on its popularization and implementation. Orienteering has been determined as a compulsory course in curriculum guidelines for physical education department made by the Ministry of Education. As an expanded track program, orienteering not only could develop physical education curriculum resources fully, give students an opportunity to go outside the camps, 
and facilitate diversified development of physical education curriculum in universities, but also could train independent thinking and ability to overcome difficulties, promote students' coordinated physical and mental development, and meet requirements of physical teaching objective better. Currently, some universities in China have started to try orienteering curriculum.

Many universities have explored and practiced orienteering curriculum, such as Southeast University, China University of Mining and Technology, Zhejiang Ocean University, etc., achieving some fruits. In foreign countries like Sweden, orienteering has been determined as one compulsory course with relative complete curriculum system, including teaching objective, teaching contents, teaching method and assessment system.

\section{B. Trainings of orienteering \\ 1) Characteristics of physical training}

Research demonstrated that orienteering pertains to an endurance exercise. Its exercise intensity could be reflected by heart rate and lactic acid value. Heart rate data indicates that orienteering is an aerobic endurance exercise to a large extent. However, the exercise intensity changes continuously in the whole competition due to the complicated conditions. Athlete body will make anaerobic exercises in many stages. As a result, anaerobic metabolism is also one important characteristic of orienteering. Attentions shall be paid to both aerobic and anaerobic trainings. Creagh put forward the physical raining method. He pointed out that aerobic training shall be one important part of physical training and shall occupy $77 \%$ of total training time. Additionally, leg strength training is also very important, because athletes have to clime slopes during competition. Experiments indicate that physical strength of athletes for cross-country race after strength training improves significantly.

Different from common running events, orienteering athletes run in complicated mountainous regions instead of flat runway. It not only requires athletes to overcome surface resistances (e.g. slopes and barriers) continuously, but also involves intelligence, including thinking, memory, attention and other cognitive qualities. Athlete brain has to check and correct his progressing routes and directions continuously, observe topographic features carefully, look for useful clues and make judgments. Such series of cognitive process will influence the progressing speed and rhythm. Therefore, physical training of orienteering is completely different from those of common running events.

\section{2) Characteristics of skill training}

According to collected foreign data, there are many researches on skills of orienteering. Many experts studied skills of orienteering from the perspective of cognitive psychology. They believed that skill is more important than physical strength for orienteering athletes[6]. Competition results of orienteering are determined by time used. It requires athletes to find out each indicated points in strange field environment within the shortest time. This is a very complicated process which includes a series of information processing, such as map reading, map observation and terrain matching, route choose, etc.

Although orienteering is a physical sport, it has higher requirements on intelligence of athletes. Athletes have to explore ways in unknown geographical environment. The whole process includes planning, thinking, memory and recognition. Murakoshi deemed that it is very important to study orienteering from the perspective of psychology. Map reading, judgment making, terrain observation and keeping map contact all involve cognitive abilities. He proposed information processing mode according to skill characteristics of orienteering. Athletes collect space environment information through sensory perception, and then screen, store and process them. Next, they make judgment according to collected information. Therefore, psychological training could be implemented in skill training according to this information processing mode.

Eccles et al. reported that orienteering athletes mainly use two heuristic strategies when selecting routes to target points: forward chaining and backward chaining. Forward chaining is to search clues and select routes from the start point to the next target point, while backward chaining is the opposite. Eccles et al. made a lot of experimental studies on these two heuristic strategies, finding that high-level orienteering athletes prefer backward chaining in searching clues and selecting routes, while low-level athletes mainly use forward chaining[fg]. This also reflects significance of planning and thinking in orienteering competition.

Research achievements on cognitive psychology provide great help to orienteering studies. According to cognitive psychology, people's cognitive process can be interpreted as an information processing process. It is a process of acquiring, processing, storing and using information, including perceptions, languages, attentions, memories, presentations, thinking, inference, etc.[9] In fact, orienteering competition is an interaction process between organism and external environmental information. Athletes acquire effective information from environment. They process it with existing experiences and store it in their memories. Next, they make judgment according to processed information and decide next action goal. Cognitive psychology also believes that in most cases, people processing visual information and spatial information without any external stimulus. Research on mental image refers to such information processing. External appearance related to matters gained and stored through visual channel is called as visual image. Research on image includes mental rotation, mental folding and image scanning. All of these characteristics conform to cognitive features of orienteering.

Map shows geospatial information in two-dimension pattern. When people are reading maps, they have to convert two-dimensional information into three-dimensional information and store it in their brains, so that they could understand map indications well. When observing practical geographical environment, athletes will scan map images and acquire related information to compare with practical terrain 
and determine progressing routes. Research has confirmed that athletes use same way to processing cognitive map in brains and images. Another research reported that people's direction information processing is similar with mental rotation. Therefore, research on images could help people to find ways more quickly and accurately in unknown environment. All of these provide theoretical psychological basis for orienteering study.

Environmental psychology proposed the concept of environmental cognition. Environmental cognition refers to the process of recognizing and understanding environment by storing, processing, understanding and recombining environmental information. It includes urban and building imagery, reading-map and way finding. E.C Tolman once proposed the concept of "cognitive map". Cognitive map refers to one internal expression of environmental space by organism. He believed that animals find ways to destination according to their cognition to conditions rather than making a series of disorganized trials and wrong behaviors. These theoretical results could help us to solve problems encountered in orienteering.

\section{Injuries of orienteering}

Abundant researches reported that ankle collateral ligament strain and contusion are most common injuries in orienteering competition. Hinernann made a survey in the sixday orienteering competition in Sweden, finding that $23.8 \%$ of injured athletes were ankle strain. Among them, $30.6 \%$ were first injury and $69.4 \%$ were old injury. Exercise-induced injury is mainly caused by inadequate training and inadequate preparation before the competition. Some experts analyzed sudden death of elite athletes. They believed that sudden death of elite athletes may be because these athletes have participated training or competitions under poor health conditions. Therefore, physical condition of athletes is a problem deserving overlook during training and competition.

\section{Orienteering map}

Only few research data on orienteering map are available. With the development of orienteering, map making standard is updating continuously. In 2003, the IOF Map Committee began to make new map making specification and standard. It establishes new International Specification for Sprint Orienteering Map (ISSOM) based on traditional International Specification for Orienteering Map (ISOM). In China, some scholars put forward their own opinions on map making. Map making is influenced by various factors, such as competition area, base map, scope of knowledge of cartographic staff, etc.

\section{Future research prospect of orienteering}

Orienteering will attract more and more people for its charm. It possesses considerable research value as either mass sports or competitive sports.

\section{A. Research on training methods for orienteering}

Orienteering integrates physical strength and intelligence. Studying intelligence is a very complicated process, but has great significance. Many foreign experts believe that intelligence in orienteering can be viewed as an information processing process. They studied cognitive process in orienteering, such as thinking, decision making, planning, memories, etc. Due to the complexity of human cognitive activities, these will remain the future research hotspot of orienteering.

Current and future research shall focus on establishing a set of effective and reasonable training methods for orienteering. Orienteering results are mainly determined by physical strength and skills. Physical training experiences of other programs could provide some references for orienteering training. Some primary research results on physical training have been achieved. Orienteering skills reflect intelligence of athletes. To develop a skill training method for orienteering, it is necessary to know intelligence of athletes showed in competition firstly. However, such intelligence involves a series of cognitive activities. Therefore, appropriate training method could only be designed with comprehension of athletes' cognition process. Establishing appropriate skill training methods for orienteering based on abovementioned theoretical research results is the main research content in future.

\section{B. Improvement of orienteering research method}

Good research program needs scientific and advanced research method. Orienteering research has to test various indicators, which needs corresponding test methods. For example, CPS could be used to test run speed and heart rate of athletes during competition. However, some indicators are difficult to be tested, such as cognitive activities (e.g. thinking and planning) of athletes. These internal behaviors couldn't be observed apparently. Therefore, it is very important to select one scientific and reasonable research method. At present, many foreign experts tested internal psychological activities of human beings by using psychological test methods like "thinking aloud". Cognitive process of athletes during competition could be known through this method. Psychological research results are conducive to test method selection. For instance, virtual reality uses computer to simulate real world and inputs substances in physical environment into computer as symbols for easy operation. Operator could determine direction and search target point in the virtual space. Test method will surely be one indispensable research content in future.

\section{Exploration of orienteering teaching system}

Orienteering is a sport integrating teaching, relaxation and entertainment. It plays an important role in personality development and shaping. Currently, orienteering has been brought into physical education in many countries. China is trying to take orienteering as a sport teaching content to enrich teaching activities and serve physical teaching objective better. However, no feasible teaching system for orienteering has been established yet for its short history in China. Therefore, physical educators still has a long way to explore this helpful sport. 


\section{Conclusion}

Research status of orienteering at home and abroad, including teaching, training, sport injury and map composition, is discussed through literature review. According to literature review, China is in its initial stage in studying orienteering, but foreign countries have reported deep researches, especially in skill training. Many experts analyzed orienteering from the perspective of cognitive psychology. Intelligence-based research on direction movement is still the future development trend.

\section{References}

[1] Y. Guoliang. Environmental Psychology. Beijing: People's Education Press, 2000

[2] Y. Guoan. Contemporary American Cognitive Psychology. Beijing: China Social Sciences Publishing House, 2001.

[3] L. Jianning Contemporary Cognitive Psychology. Shanghai: Shanghai Educational Publishing House, 2003.

[4] W. Yuanlin. Full Manual for Orienteering. Guangzhou: Southern Daily Press, 2003. 